\title{
Influence of Angle Ply Orientation on Tensile Properties of Carbon/Glass Hybrid Composite
}

\author{
M. N. GuruRaja ${ }^{*}$ A. N. HariRao \\ Department of Mechanical Engineering, S.J. College of Engineering, Mysore, India \\ Email: "gurusmn@gmail.com, hariraoan@gmail.com
}

Received April 28, 2013; revised June 8, 2013; accepted June 18, 2013

Copyright (C) 2013 M. N. GuruRaja, A. N. HariRao. This is an open access article distributed under the Creative Commons Attribution License, which permits unrestricted use, distribution, and reproduction in any medium, provided the original work is properly cited.

\begin{abstract}
Hybrid composites are considered materials of great potential for engineering applications. One advantage of hybrid composite materials for the designer is that the properties of a composite can be controlled to a considerable extent by the choice of fibers and matrix and by adjusting the orientation of the fiber. The scope for this tailoring of the properties of the material is much greater, however, when different kinds of fiber orientations are incorporated in the same resin matrix. For the study of potential of these materials, in this work specimens were prepared with different angle ply orientation of carbon/glass hybrid with epoxy resin as an adhesive. Three orientations viz $0^{\circ} / 90^{\circ}, 45^{\circ} / 45^{\circ}$ and $30^{\circ} / 60^{\circ}$ were considered for studies. Mechanical properties such as tensile strength, tensile modulus, \& peak load of the hybrid composites were determined as per ASTM standards. Vacuum bagging technique was adopted for the fabrication of hybrid specimens. It was observed that angle ply orientation at $0^{\circ} / 90^{\circ}$ showed significant increase in tensile properties as compared to other orientation. Scanning electron micrographs of fractured surfaces were used for a qualitative evaluation of interfacial properties of woven carbon-glass hybrid composites. These results indicated that carbon-glass hybrid composites offered the merits of synthetic fibers.
\end{abstract}

Keywords: Hybrid; Tensile Modulus; Flexural Modulus; Carbon/Glass; Orientation

\section{Introduction}

A composite is a structural material that consists of two or more combined constituents that are combined at a macroscopic level and are not soluble in each other. One constituent is called reinforcing phase and one in which it is embedded is called the matrix. The reinforcing phase material may be in the form of fibers, particles or flake. The matrix phase materials are generally continuous. The roles of matrix in composite materials are to give shape to the composite part, protect the reinforcements to the environment, transfer loads to reinforcements and toughness of material, together with reinforcements. Composite materials are used for Automobile, Ships, Aircraft, sports goods and so on [1-3].

Hybrid materials are composites consisting of two constituents at the nanometer or molecular level. Commonly one of these compounds is inorganic and the other one is organic in nature. Thus, they differ from traditional composites where the constituents are at the macroscopic (micrometer to millimeter level). Mixing at the microsco-

"Corresponding author. pic scale leads to a more homogeneous material that either shows characteristics in between the two original phases or even new properties. Purpose of hybridization is to increase a resistance against the interlaminar toughness that cannot be obtained with only conventional composite material. The use of hybrid materials in composite structural is becoming more nowadays [4], and the fibers can be arranged in various orientations during preparation of composite. However, there are other factors such as cost, weight, post-failure behavior leading the designer to use hybridization in order to tailor the material to exact needs under design [5]. Epoxy resin is used in this hybrid composite because it provides a unique balance of chemical and mechanical properties combined with extreme processing versatility. In all cases, thermo set resins may be tailored to some degree to satisfy particular requirements [6].

Hybrid laminated composites are prepared by stacking sheets of Glass/Carbon fibers to required orientation to form angle ply laminates. An individual structural glass fiber is both stiff in tensile and compression [7]. Thickness of hybrid laminate is maintained for $3 \mathrm{~mm}$ as per 
ASTM standard [8] i.e. 10 plies are located symmetrically at ply position to get required orientation angle ply composites and which is prepared by hand-laid up with vacuum bag technique.

\section{Experimental Procedure}

\subsection{Specimen Fabrication}

E-glass fiber grade $360 \mathrm{GSM} \&$ diameter of glass fiber is $0.25 \mathrm{~mm}$ diameter is tailored with carbon fiber $0.25 \mathrm{~mm}$ diameter to prepare bi-woven clothes. The thickness of the cloth is $0.3 \mathrm{~mm}$ which are stacked layer by layer about 10 layers to attain required thickness.

During preparation of laminated required orientation of fiber is carried out for angle ply composites. For $\left(0^{\circ} \%\right.$ $90^{\circ}$ ) glass fiber placed at $90^{\circ}$ carbon fiber at $0^{\circ}$, for $60^{\circ} \%$ $30^{\circ}$ glass fiber is placed at $60^{\circ}$ and carbon fiber at $30^{\circ}$, for $\pm 45^{\circ}$ glass is placed in $+45^{\circ}$ \& carbon at $-45^{\circ}$.

Epoxy resins, also known as polyepoxides, grade LY556 HY951 resin used. It consists of monomers or short chain polymers with epoxide group at its end. Which contain epoxide groups co-reactants are often referred to as hardeners or curatives, and the cross-linking reaction is commonly referred to as curing. Laminates are prepared by hand-laid-up process using vacuum bag technique. After preparation of laminates it is cured in a reheating furnace to $100^{\circ} \mathrm{C}$ up to $2 \mathrm{hrs}$. After curing, specimens are fabricated as per the ASTM standard as shown in Figures 1-3.

\subsection{Tensile Testing}

Tensile testing is a fundamental mechanical testing method in which a sample is subjected to uniaxial tension until failure. The results from the test are commonly used to select a material for an application, for quality control, and to predict how a material will react under other types of forces. Properties such as ultimate tensile strength, maximum elongation and reduction in area can be determined. In this test specimen is loaded in a very controlled



Figure $1.0^{\circ} / 90^{\circ}$ Angle ply laminate.

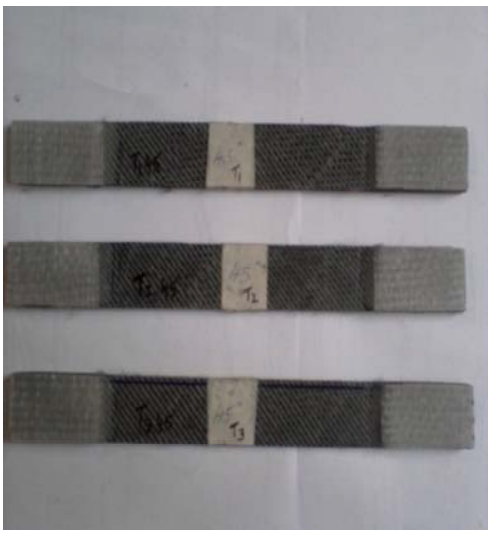

Figure $2.45^{\circ}$ Angle ply laminate.

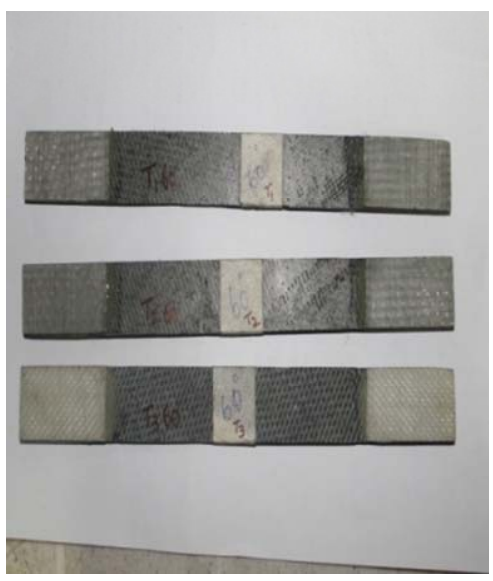

Figure $3.60^{\circ} / 30^{\circ}$ Angle ply laminate.

manner while measuring the applied load and the elongation of the specimen over some distance.

Specimens are prepared as per ASTM D3039 standard, which consist tabs at either ends. The universal testing machine (UTM) is used for testing with higher accuracy, the maximum capacity of machine $100 \mathrm{KN}$ is used for testing, which operated on electronic control servo mechanism. Speed rate is $2 \mathrm{~mm} / \mathrm{min}$; the specimen is fixed between lower crosshead \& intermediate cross head as shown in Figures 4 and 5.

\section{Results \& Discussions (Refer to Tables 1-3)}

The 10 layer carbon/glass hybrid composites exhibited average tensile strength values of $36.05 \mathrm{GPa}$ for ply orientation of $0^{\circ} / 90^{\circ}, 11.38 \mathrm{GPa}$ for $\pm 45^{\circ}$, and $13.64 \mathrm{GPa}$ for $30^{\circ} / 60^{\circ}$. The $0^{\circ} / 90^{\circ}$ ply orientation increases the mechanical properties of carbon/glass mats $[9,10]$. When the peak stress of angle ply $0^{\circ} / 90^{\circ}$ when compared with \pm $45^{\circ}$ is found to be $18.6 \%$ greater, similarly when it is compared with $60^{\circ} / 30^{\circ}$ it is found that $24.99 \%$ is greater than that angle ply composite material. When the peak load of angle ply $0^{\circ} / 90^{\circ}$ is compared with $\pm 45^{\circ}$, it is 
Table 1 . For $0^{\circ} / 90^{\circ}$ elongation, tensile modulus of carbon/glass hybrid composite.

\begin{tabular}{cccccc}
\hline S1. No. & $\begin{array}{c}\text { Sample } \\
\text { number }\end{array}$ & $\begin{array}{c}\text { Stacking } \\
\text { sequence }\end{array}$ & $\begin{array}{c}\text { Elongation at break } \\
(\%)\end{array}$ & $\begin{array}{c}\text { Average elongation at } \\
\text { break (\%) }\end{array}$ & $\begin{array}{c}\text { Tensile modulus } \\
(\mathrm{GPa})\end{array}$ \\
\hline 1 & $0^{\circ} / 90^{\circ}$ & $1.7 \%$ & $\begin{array}{c}\text { Average tensile modulus } \\
(\mathrm{GPa})\end{array}$ \\
2 & $\mathrm{~T} 1$ & $0^{\circ} / 90^{\circ}$ & $0.8 \%$ & $1.33 \%$ & 34.90 \\
3 & $\mathrm{~T} 2$ & $0^{\circ} / 90^{\circ}$ & $1.5 \%$ & 36.056 \\
\hline
\end{tabular}

Table 2. For $\pm 45^{\circ}$ elongation, tensile modulus of carbon/glass hybrid composite.

\begin{tabular}{|c|c|c|c|c|c|c|}
\hline S1. No. & $\begin{array}{l}\text { Sample } \\
\text { number }\end{array}$ & $\begin{array}{l}\text { Stacking } \\
\text { sequence }\end{array}$ & $\begin{array}{c}\text { Elongation at break } \\
(\%)\end{array}$ & $\begin{array}{c}\text { Average elongation at } \\
\text { break (\%) }\end{array}$ & $\begin{array}{l}\text { Tensile modulus } \\
\quad(\mathrm{GPa})\end{array}$ & $\begin{array}{l}\text { Average tensile modulus } \\
(\mathrm{GPa})\end{array}$ \\
\hline 1 & $\mathrm{~T} 1$ & $\pm 45^{\circ}$ & $1.2 \%$ & & 11.289 & \\
\hline 2 & $\mathrm{~T} 2$ & $\pm 45^{\circ}$ & $0.95 \%$ & $1.05 \%$ & 11.568 & 11.376 \\
\hline 3 & $\mathrm{~T} 3$ & $\pm 45^{\circ}$ & $1 \%$ & & 11.282 & \\
\hline
\end{tabular}

Table 3 . For $60^{\circ} / 30^{\circ}$ elongation, tensile modulus of carbon/glass hybrid composite.

\begin{tabular}{|c|c|c|c|c|c|c|}
\hline Sl. No. & $\begin{array}{l}\text { Sample } \\
\text { number }\end{array}$ & $\begin{array}{l}\text { Stacking } \\
\text { sequence }\end{array}$ & $\begin{array}{c}\text { Elongation at break } \\
(\%)\end{array}$ & $\begin{array}{c}\text { Average elongation at } \\
\text { break (\%) }\end{array}$ & $\begin{array}{l}\text { Tensile modulus } \\
\text { (GPa) }\end{array}$ & $\begin{array}{l}\text { Average tensile dulus } \\
\text { (GPa) }\end{array}$ \\
\hline 1 & $\mathrm{~T} 1$ & $60^{\circ} / 30^{\circ}$ & $0.81 \%$ & & 13.698 & \\
\hline 2 & $\mathrm{~T} 2$ & $60^{\circ} / 30^{\circ}$ & $0.57 \%$ & $0.86 \%$ & 14.14 & 13.633 \\
\hline 3 & $\mathrm{~T} 3$ & $60^{\circ} / 30^{\circ}$ & $1.19 \%$ & & 13.08 & \\
\hline
\end{tabular}

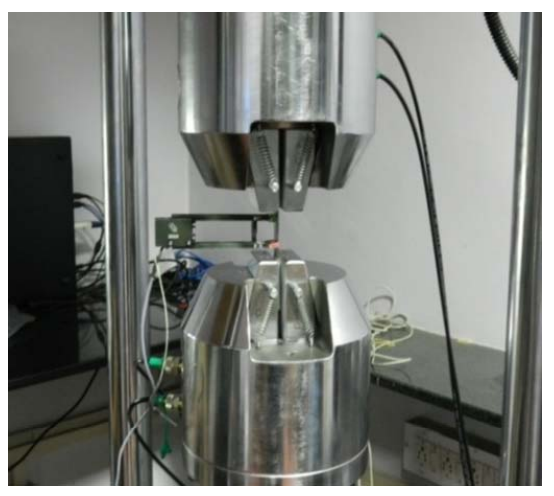

Figure 4. Specimen loaded in testing machine.

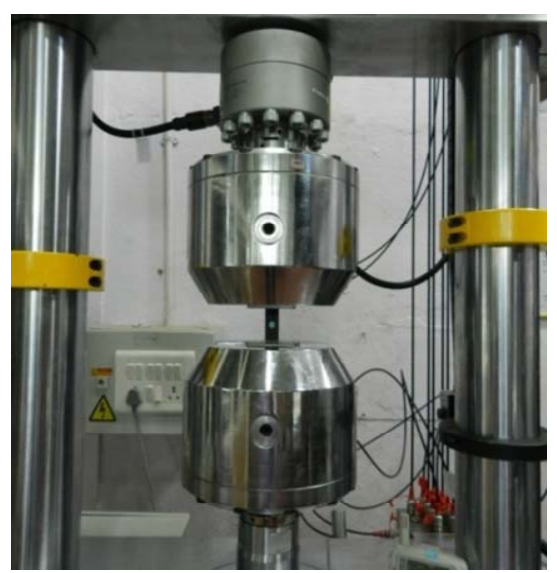

Figure 5. Specimen loaded in universal testing machine. found that $18.11 \%$ is greater, similarly when it is compared with $60^{\circ} / 30^{\circ}$ it is found that $24.69 \%$ is greater than that angle ply composite material. When the modulus of angle ply $0^{\circ} / 90^{\circ}$ is compared with $\pm 45^{\circ}$, it is found that $31.56 \%$ is greater, similarly, when it is compared with $60^{\circ} / 30^{\circ}$, it is found that $37.83 \%$ is greater than that angle ply composite material.

\section{Failure Analysis}

Figure 6 shows the matrix cracking of hybrid specimens under the maximum stress $\sigma \max =438 \mathrm{MPa}$; the density is defined as the average number of matrix cracks in each hybrid layer per unit length in the longitudinal direction. Figure 7 shows the side surface of CFRP \& GFRP hybrid specimens with matrix crack, delamination under maximum stress $\sigma \max =438 \mathrm{MPa}$. The matrix cracks of hybrid specimens are nucleated in the central $45^{\circ}$ plies of the angle-ply specimen and the delaminations of hybrid specimens are observed to appear from the specimen surface. The damage initiation is delayed by the interleaving in the angle-ply hybrid specimens. It is observed that from the experiment carbon fibers are damaged more than the glass fibers as shown in Figures 7 and 8, since carbon is more brittle in nature than glass fibers. On the other hand, damage initiation at $\pm 45^{\circ}$ and $30^{\circ} / 60^{\circ}$ orientation is found to be less significant.

The SEM analyses of fractured surfaces after the mechanical tests are shown in Figures 8 and 9. The matrix 


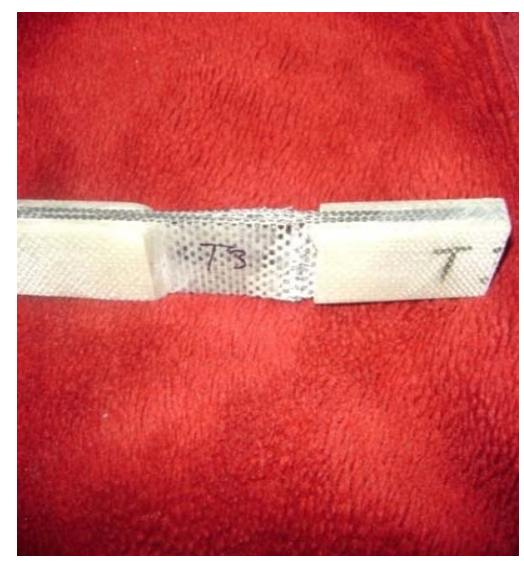

Figure 6. Failure of tensile specimen.

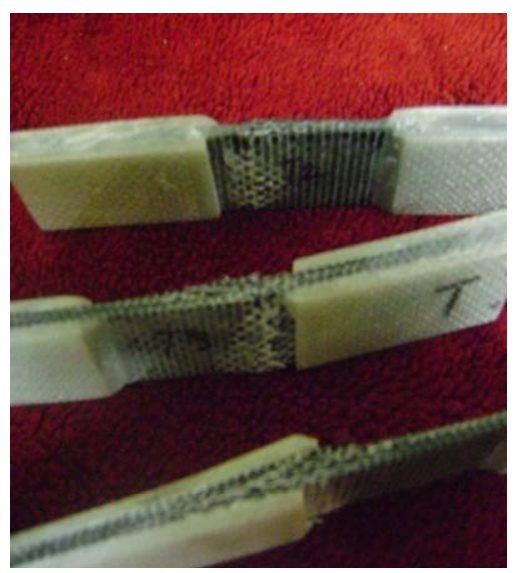

Figure 7. Failure of tensile specimen.

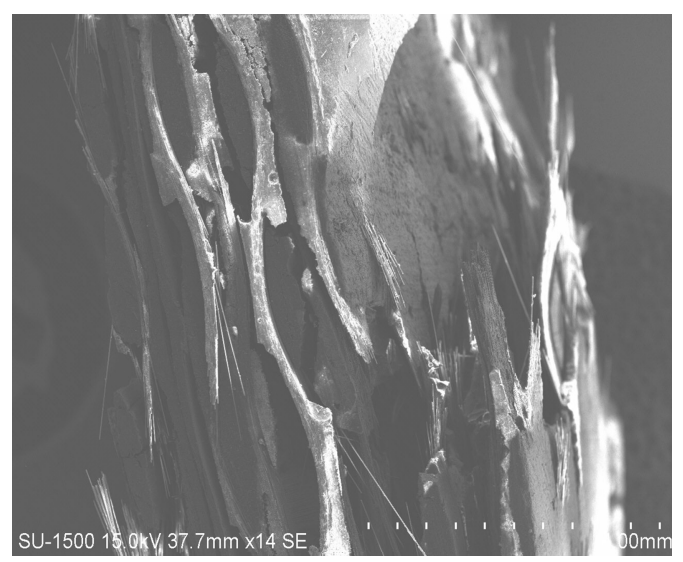

Figure 8. SEM image of void content in glass/carbon specimens.

cracking, formation of fracture line, fiber pull out and fiber-resin compatibility were studied using SEM images. The observations revealed that the laceration was found on glass fiber due to the applied loads during tests. The formation of voids due to fiber pull out was found in fibers because of poor resin compatibility of synthetic fibers [11]. The matrix cracking and fracture lines were

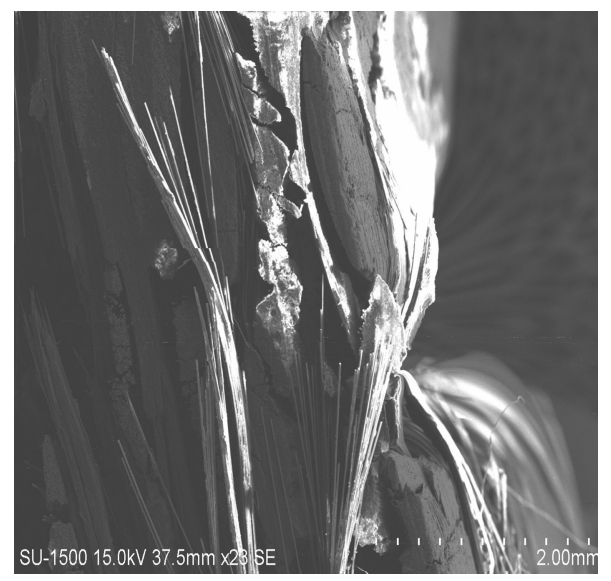

Figure 9. SEM image of glass/carbon specimens after tensile fracture from top.

formed on the surfaces that exhibited poor interfacial bond. However, inclusion of carbon fibers exhibited the improvement in strength [12] and thus "hybridization effect" was noticed in the specimens.

\section{Conclusions}

Experiments were conducted on Glass fiber/Carbon fiber/Epoxy resin hybrid angle ply laminates with different fiber orientation to characterize the tensile properties. The following conclusions were drawn and recorded:

1) The glass fibers fail more quickly than the carbon fibers. The five layers of glass plies at front opposed the applied load greater than the five layers of glass plies at back in woven glass/carbon hybrid composites.

2) Incorporation of woven glass/carbon in extreme plies of composites enhances the improved mechanical properties of hybrid composites.

3) The mechanical properties of composite materials depend upon the structure of the material, and also depend on the volume fraction, interfaces between components.

4) Failures of composite materials include the fracture of fibers, fracture of matrix in tension normal to the fibers. And the nature of failure also depends on the angle ply between the fibers and specimen's axis.

5) During specimen preparation angle ply hybrid composite for $0^{\circ} / 90^{\circ}$ orientation, glass fiber is placed in $90^{\circ}$ and carbon fiber placed in $0^{\circ}$, because the glass fiber is more ductile than carbon fiber.

6) During specimen preparation angle ply hybrid composite for $0^{\circ} / 90^{\circ}$ orientation, glass fiber is placed in $90^{\circ}$ and carbon fiber placed in $0^{\circ}$, because the glass fiber is more ductile than carbon fiber.

7) In tensile test load is acting in axial direction, since glass fiber is in the direction of load which carries maximum load and also could be transferred to the carbon fiber. Carbon fiber is brittle in nature which fails first then 
glass fiber will fails.

8) In other types of specimen i.e. for $60^{\circ} / 30^{\circ}$ and $\pm 45^{\circ}$ orientation of hybrid composite degree of orientation for glass fiber is less, because the less the degree of orientation is, the less the strength and stiffness of materials will be.

9) Scanning electron micrographs showed that the fiber pull-out started from glass fibers and good interfacial bond was developed between woven glass and epoxy resin matrix. However, some micrographs revealed the presence of voids, thus degrading the strength.

From above we concluded that if we calculate mechanical properties for other orientations, the maximum properties can be obtained only in $0^{\circ} / 90^{\circ}$ angle ply orientation.

Further research work needs to be carried out in the development of hybrid fiber-reinforced composites by the inclusion of filler material and fiber treatment for getting improved mechanical properties.

\section{REFERENCES}

[1] S. R. Swanson, "Introduction to Design and Analysis with Advanced Composite Materials," Prentice Hall, Englewood Cliffs, 1997.

[2] X. Yong, "Gan Effect of Interface on Mechanical Properties of Advanced Composite Materials," International Journal of Molecular Sciences, Vol. 10, No. 3390, 2009, pp. 5115-5134.

[3] R. Marissen, "Flight Simulation Behavior of Aramid Reinforced Aluminum Laminates," Engineering Fracture
Mechanics, Vol. 19, No. 2, 1984, pp. 261-277. doi:10.1016/0013-7944(84)90021-3

[4] Tensile Properties and Fatigue Characteristics of Hybrid Composites with Non-Woven Carbon Tissue," International Journal of Fatigue, Vol. 207, No. 4, pp. 397-405.

[5] ASM Data Hand Book, 195.

[6] G. Kretsis, "A Review of the Tensile, Compressive, Flexural and Shear Properties of Hybrid Fibre Reinforced Plastics," Composites, Vol. 18, No. 1, 1987, pp. 13-23.

[7] J. Harding and L. M. Welsh, "A Tensile Testing Technique for Fibre-Reinforced Composites at Impact Rates of Strain," Journal of Materials Science, Vol. 18, No. 6, 1983, pp. 1810-1826.

[8] J. Cho, J. Y. Chen and I. M. Daniel, "Mechanical Enhancement of Carbon Fiber/Epoxy Composites by Graphite Nano Platelet Reinforcement," Scripta Materialia, Vol. 56, No. 8, 2007, pp. 685-688.

[9] Standard Test Method for Tensile Properties of Polymer Matrix Composite Materials, ASTM D 3039-95.

[10] P. K. Mallick, "Fibres Reinforced Composites-Materials, Manufacturing and Design," 2nd Edition, Marcel Dekker, Inc., New York, 1993, pp. 243-244.

[11] Emiliasabau et al., "Mechanical Characterics of Composite Materials Obtained by Different Technologies," Academic Journal of manufacturing Engineering, Vol. 9, No. 3, 2011, pp. 100-105.

[12] S. Jayabal et al., "Effect of Glass Hybridization and Staking Sequence on Mechanical Behaviour of Interply CoirGlass Hybrid Laminate," Bulletin of Material Science, Vol. 34, No. 2, 2011, pp. 293-298. doi:10.1007/s12034-011-0081-9 